\title{
Research on College Students Sports Cognition of sports information under the Internet Environment
}

\author{
Guohua Shao \\ Institute of Physical Education, Inner Mongolia Normal University, Hohhot 010022, Inner Mongolia, \\ China
}

Keywords: sports news of contemporary college students'; physical quality influence

\begin{abstract}
We found that sports news. All levels of television programs, in today's society sports information has become the modern media in an important part, play a decisive role. The newspapers magazines of their publications, sports version of the content of expanding, sports news has become an important means to attract the audience of their. With the continuous popularity of sports information, it has become a people's leisure time entertainment, the sports information pursued mostly for young men, and our students because of their young, vibrant, active characteristics into sports information pursued in a main force. They occupied the absolute superiority in the majority of sports news audience, and demonstrated to the sports news of great loyalty and consumption, which makes them into a group with the majority of the mass media in popular. In this paper, the author will carry on in-depth analysis to this phenomenon, and according to the practical results of sports information on contemporary college student's sports cognition function is briefly discussed.
\end{abstract}

\section{Introduction}

Because of traditional teaching mode and influence, the traditional teaching method is not only popular in education, but also makes the sports teaching in Colleges and universities have also been affected. Traditional sports teaching in Colleges and universities will be for sports skill teaching in the first place, it is no ground for blame, but also will train students' Humanity Quality Education of the left behind, which makes our students in some of the basic physical healthy knowledge is extremely scarce, such as health care knowledge, sports appreciation knowledge, sports evaluation etc.

Table 1 Lack of participation in sports activities

\begin{tabular}{|c|}
\hline A survey of contemporary college students, sports cognitive status \\
\hline lack of participation in sports activities \\
\hline the sports moral accomplishment is low, does not have its own personality \\
\hline
\end{tabular}

\section{Lack of participation in sports activities}

Show according to relevant data survey: physical health status of university students in China is showing a declining trend, this is because the majority of college are excessively will all look into to strengthen students' intellectual, make sports culture can not be caused by diffusion in the campus. Exam oriented education in such circumstances, our college students generally lack the sense of participation in sports, but also makes them lack in each unit of various sports competitions and activities of interest, so that their sport participation consciousness and the team cooperation consciousness cannot get due development. 


\section{The sports moral accomplishment is low, does not have its own personality}

Now in the University, the universal existence of such situation, sports teacher only pay attention to technology teaching and not from the physical education students itself, and the final score is also due to various reasons which makes the sports fair principle basically ignored. The present situation of the series will lead us to our college students for sports teachers and sports classes generate strong emotions. After the investigation, the author found that many contemporary college students though sports in the public or private organizations to participate in, but many of them are extracurricular physical exercise in which a large part of the reason is actually received the influence of other classmates. This to our reflects the current community college students lack their own sports personality, many students are objective or manner of physical exercise are from around the students recommended or influence, the crowd not according to their own circumstances and in sports activities situation makes the students' sports personality should not show.

\section{The sports news on the sports behavior of College Students' literacy}

The author of this article before writing to the students around as a "sports information about what effect" on sports cognition or behavior questionnaire, according to the questionnaire information I returned briefly to statistics, found in the survey, about $85 \%$ of girls and $74 \%$ of boys that their sports cognition or behavior affected the sports information. The influence of sports on the sports information behavior of College Students' literacy is mainly manifested in the following aspects:

Table 2 The sports news on the sports behavior of College Students' literacy

\begin{tabular}{|c|}
\hline More active participation in various sports activities \\
\hline Through the sports information access to the content related to sports hot. \\
\hline The dissemination of sports information on its own sports level \\
\hline Has a positive impact and a certain level of improvement.. \\
\hline Because sports information publicity made itself develop exercise habits. \\
\hline
\end{tabular}

(a) More actively participate in various sports activities.

Many students reflect the propagation of sports news makes them more about sports knowledge including physical fitness, fitness knowledge, all kinds of games, many athletes understanding. And a lot of sports information and so they gradually strengthened to the favorite sports, and actively participate in various sports activities in school or organization of students.

(b) Through the sports information access to the content related to sports hot. According to the survey, the author let the students answer "whether the hot content in sports news and sports behavior adjustment" own, results show that many students interest in sports activities is not fixed and unchangeable, many students because of the lack of exercise their own favorite, so generally have more sports level equilibrium. This point from a certain point of view is for students to provide basis for selecting new sport at any time, because there is no fixed preferences project, so the sports information on their influence to try different sports activities is relatively large.

(c) Of which about $48 \%$ of college students said, the dissemination of sports information on its own sports level has a positive impact and a certain level of improvement. Through the survey results, we can see that the sports media has been part of the college students to accept and gradually got their approval and love, the to further improve the students interest in sports and help them master more sports skills have positive effect.

(d) Because of sports information publicity made itself develop exercise habits.

The effect of a large part of the students about $78 \%$ of sports information to recognize the state, they think they have to insist on physical exercise habit a lot of credit lies in the sports information media. Sports information media to help them get the entertainment and sports opportunities in 
learning idle, and in the process of their physical and mental pleasure, help themselves through physical activity from the tension in the study received physical and mental relaxation and adjust the opportunity.

\section{Some suggestions to strengthen to improve college students' physical quality of sports information}

Since the sports media information of physical training and sports accomplishment to help our students improve has a positive role in this, how to strengthen the positive effects of physical information on college student sports quality is our each people need to consider the issue of. The author puts forward some own suggestions or measures.

Table 3 Some suggestions to strengthen to improve college students' physical quality of sports information

The expansion of sports news coverage and effective entertainment in our real media, sports information is rich and colorful, but there is accomplishment fewer and fewer.

Media and the actual extension of student path.

Give full play to the role of sports information to help students find Personality.

(a) The expansion of sports news coverage and effective entertainment in our real media, sports information is rich and colorful, but there is "sports information is the connotation, accomplishment" fewer and fewer. A lot of reading the sports information college students begin their own curiosity and interest based, which focus on the sports media, so that they can really learn the physical exercise useful and benefit from in to meet their own psychological adventure at the same time. Face with the actual reality of the sports information media.

Problems, such as disorder, personality deficiencies, repeat content too high and so on we should take active response measures to restore the sports press clear and positive state. Therefore, this requires us the news media in use and time to pursue their own news, useful information can also expand the connotation of sports news.

Cover scope and increase the depth and intensity of the reports of sports news. At the same time, the status of entertainment in sports news is also play a decisive role, sports news entertainment is entertainment should strengthen to replace other functions and gradually become the main function of sports news. The students are interested in sports information depends entirely on the show entertaining sports news, many students began to focus first can always get something interesting from the sports news, like sports information and then they will be better, and through continuous disintegration education news information and ultimately improve their physical quality objective.

(b) News media and the actual extension of student sports accomplishment training path.

In order to realize the construction of sports culture in universities to keep pace with the times, in order to make the university sports culture literacy education can strive for further improvement, we need the news media and the propagation path of integration of cultivating the students' literacy practice, through the reorganization of the operation of campus media, strengthen about sports knowledge of propaganda in schools. With the development of campus media resources and expanding, many universities have digital technology to their own network and radio as the platform. But because a lot of campus between media because in the independent state that the lack of interaction between media, which caused great waste of resources. Therefore, in the face of this new situation, campus media should remain as a basic principle of school services at the same time, we and the actual integration so as to realize the way of expanding student sports accomplishment. Through integration of campus media and practical, our students have a better understanding of the relevant knowledge of sports including its origin, development and basic knowledge, students can learn in the course of the development of the human society, the important role of sports. 
In addition, some of the sports culture knowledge lectures or knowledge contest and other activities also need attention and developed by the school, through such a series of media in practical ways, to help our students to improve their knowledge of physical education in the physical quality influence imperceptibly and strong environment capacity and level of sports.

(c) Give full play to the role of sports information to help students find their own sports personality

Physical education in Colleges and universities should make full use of modern media tools, give full play to the role of sports information to help students find their own personality and preferences in sports, this can be through the establishment of a sports information screening system to help students realize their management of sports information and find themselves interested in sports or the purpose of knowledge. The students need a their favorite sports to complete their own sports personality, students can find and his like-minded partners to explore the physical problems, show the culture or by carrying out sports activities and sports competition and other ways to achieve their own sports personality, which can not only enrich the sports our theoretical knowledge, but also can formed to promote the sports cultural literacy of university students and improve the good.

\section{Conclusion}

College students can contact with different media system get what they need information or content of sports, sports news as college students are the most widespread attention from the media form, and improve the training of physical quality of college students has play a decisive role of. Sports information in the process of communication is not only makes the students obtain the entertainment effect, more important is that he is way for students to understand the sports cultural connotation and profound spirit, it can affect the students in a certain extent, the sports consciousness, and ultimately to their sports behaviors will influence the. Thus the sports news on college students was so great, it enables students with different sports culture communication distance to reduce it to our students, spread around the sports culture or information provided the way. Therefore, in the face of uneven, some good and some bad sports news and information, school, teachers and students of our own.

Should improve their vigilance and for screening ability of physical information. In order to realize the sports information to students' sports consciousness, skills, has a positive role, you need to realize the function of sports news to improve college students' physical and moral literacy through the efforts and actions, to help students can still be in after entering into the society.

Thus, in this piece of guide way and behavior of college teachers is an important factor to consider, how to realize the strengthening of the role of sports information on Sports Cognition of contemporary college students, should include students themselves, the school, the society, the media and other parties to work together, work together to build a positive and healthy.

\section{References}

[1] Mass Communization: A Liberal Arts Perspective. . 1994

[2] M. The Agenda-Setting Function of Mass Media". Public Opinion. 1972

[3] Behavior Analysis in Physical Education. The Journal of Physical Education Recreation 2001

[4] What do we really know about daytime serial listeners? Radio research, 1944 